\title{
Evaluation of Stress-Relaxation in Fruit Tissue
}

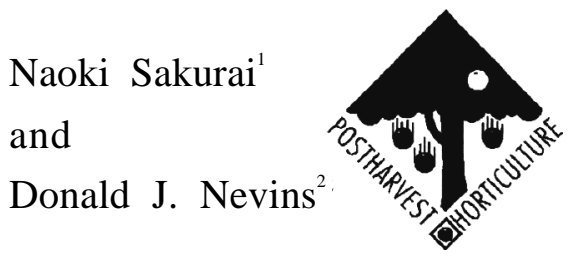

Additional index words. fruit softening, viscosity, texture, ripening, cell walls, Lycopersicon

Summary. During fruit softening, tissue texture characteristics may be documented by stress-relaxation analysis. Data were collected when a conical probe was inserted into tomato tissue to a prescribed depth. Five parameters were resolved during the load decay. By this method the elastic (firmness or softness) and viscous characteristics of the fruit tissue were identified. The initial load required to insert the probe into the fruit reflects tissue elasticity, while the two time-dependent parameters, one reflecting the initial response time and the other corresponding to the point when the tissue ceases to accommodate the imposed load, reflect tissue viscosity. The technique is also applicable for the measurement of processed materials, viz. canned tomatoes and paste, when modified probes are used.

$\mathrm{F}$ ruit maturation represents a sequence of coordinated biochemical processes, including ethylene evolution, climacteric respiration, pigment accumulation, and tissue softening. Firmness of the fruit is a crucial issue for the quality management, processing and handling, and transportation of the fruits. Softening of fruit tissues, either to enhance consumer acceptance or as a factor influencing shelf-life, must be attributed to the changes in the expression of physical or mechanical propertiesproperties that are based on changes in the chemical structure of cell walls. Textural changes during fruit soften-

Department of Environmental Studies, Faculty of Integrated Arts \& Sciences, Hiroshima University, Hiroshima 730, Japan.

${ }^{2}$ Department of Vegetable Crops, University of California, Davis, CA 95616. 
ing are believed to be caused by the degradation of cell wall polysaccharides (Brady 1987; Fisher and Bennett, 1991; Huber 1983a). In fact, an index of green maturity is the chemical determination of green pea maturity of alcohol-insoluble solids, a test that roughly represents the quantity of cell wall polysaccharides (Pomeranz and Meloan, 1987).

There is ample evidence to show that, among the various wall polysaccharides, pectic (acidic) polysaccharides are solubilized during the softening of many fruits such as, tomato, melon, strawberry, cherry, peach, pear, and apple. In addition to the pectin solubilization, Huber (1983b) reported that hemicellulosic (neutral) polysaccharides also were degraded in tomato pericarp tissues. The monitoring of degradation of specific wall polysaccharides might serve as an index for fruit softening. Chemical analysis of wall polysaccharides, however, is tedious and not practical as a routine protocol for evaluation of fruit tissue quality. Therefore, physical and mechanical techniques for assessing fruit quality have been developed. Instruments for the measurement of fruit texture include compressimeters, penetrometers, shear-testing devices, and, to a lesser extent, instruments that measure sonic behavior and energy consumption during grinding (Pomeranz and Meloan, 1987). A simple, versatile physical technique to follow the consequences of degradation of wall polysaccharides in fruit tissues may be effective in evaluating fruit texture.

\section{Physical evaluation of fruit softening}

Most of the mechanical tests measure the force required to crush, puncture, or shear fruit samples (Brady et al., 1983, Ahrens and Huber 1990). Although Lynch et al. (1959) reported that there was a correlation of instrument readings with the alcohol-insoluble solids content, the methods did not predict the degradation of wall polysaccharides directly. This probably resulted from the fact that the measured force primarily represented elastic properties of the sample, while cell walls would be expected to have viscous as well as elastic properties (viscoelasticity). Stress-relaxation analysis is suitable for measuring the mechanical properties of tissue that exhibit viscoelastic properties. The stress-relaxation technique was applied first to fruit tissues by Somers (1965). He recognized that fruit tissues show viscoelastic properties derived from the mechanical properties of the cell walls, but he was unable to evaluate qualitatively tissue texture in terms of a stressrelaxation curve because an appropriate mathematical treatment for numerical expression was unavailable. A comprehensive mathematically described stress-relaxation technique was first applied to the measurement of cell walls in stems by Yamamoto et al. (1970). In that case, the cell wall of pea stems was stretched by an Instron tensile tester, and the load decay (relaxation) was recorded after stretching. The decay of the load was simulated by the following equation based on a Maxwell-viscoelastic model [Eq. 1].

$\operatorname{Load}(\%)=R\left(\log _{e} \frac{t+T_{m}}{t+T_{0}}\right)+C \quad[$ Eq. 1]

where $R$ is relaxation rate, $T_{m}$ the time when the decay stops, $\mathrm{T}_{0}$ the time when the decay starts, and $\mathrm{C}$ the residual load after $\mathrm{T}_{\mathrm{m}}$ (Fig. 1). Note that the load is expressed as a percentage. The fact that the load decay was expressed fully by the above equation based on the Maxwell-viscoelastic model demonstrates that plant cell walls exhibit viscoelasticity. When auxin, a growth stimulator, was applied to the stem tissue, it mediated a decrease in $\mathrm{T}_{0}$ of the cell wall specimen, a change correlated with the growth of stems. The decrease in $\mathrm{T}_{0}$ mediated by auxin was found in many plant systems, such as coleoptiles of oat, rice, corn, and barley; stems of pea, bean, and squash; and tuber tissues of Jerusalem artichoke (Masuda, 1990). Therefore, the decrease in $\mathrm{T}_{0}$ values has been assigned as an index for wall loosening phenomena prerequisite for growth. Cell wall-loosening is caused by the degradation of wall polysaccharides (described below). Stress-relaxation analysis appears to detect those changes in cell walls.

\section{Relation between physical and biochemical changes in the cell walls}

Changes in wall polysaccharides associated with auxin-induced wallloosening processes in stems was described first by Loescher and Nevins

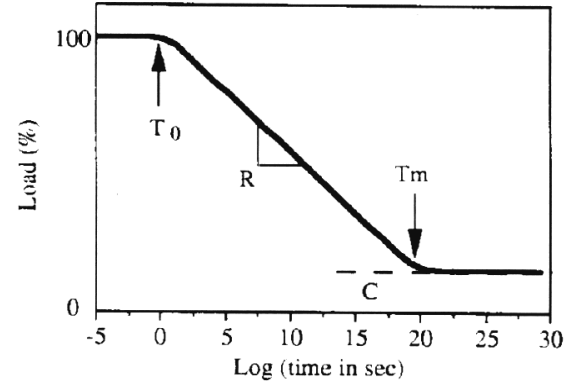

Fig. 1. Stress-relaxation curve related to four stress-relaxation parameters. When the initial load is expressed as $100 \%$, the stressrelaxation curve is expressed by four parameters, $T_{b}, R, T_{m}$ and $C$. Note that the $x$ axis is expressed as logarithmic scale of time in seconds. If the forcing frame with an optional transducer module is used, one can achieve a fixed insertion depth of the probe into the tissue. Once the insertion depth is fixed, the initial load when the probe is stopped can be used as the fifth parameter.

(1972). When auxin promotes elongation growth of oat, rice, or barley coleoptile tissues, one of the main wall constituents $(\beta-1,3$ : 1,4-glucans) in cereal plants is degraded. The degradation always was accompanied by the decrease in $\mathrm{T}_{0}$ obtained by the stressrelaxation method (Sakurai et al., 1977; Sakurai and Masuda, 1978; Sakurai et al., 1979; Zarra and Masuda, 1979). In dicotyledonous plants, however, the salient changes in wall polysaccharides during auxin-induced growth was found in xyloglucans (Hayashi, 1989; Nishitani and Masuda, 1983; Wakabayashi et al., 1991). The stress-relaxation parameters adjust in response to auxin-induced changes in xyloglucan during elongation growth of dicot plant stems (Masuda, 1990; Sakurai, 1991).

The time-dependent parameters acquired during stress-relaxation analysis $\left(T_{0}\right.$ and $\left.T_{m}\right)$ represent viscous properties of the cell walls. Wall polysaccharides consist of hundreds to thousands of monomeric sugar molecules. Cleavage of any one of the glycosidic linkages within wall polysaccharides leads to depolymerization. The loss of content and/or depolymerization of wall polysaccharides lead to the decrease in viscosity of the cell wall matrix (Sakurai, 1991). Conventional methods for measuring fruit tissue texture do not afford information necessary to resolve viscous properties of cell walls in terms of changes in wall polysaccharides. The stressrelaxation method represents the only 
technique known currently for determining viscous properties as well as elastic properties of the cell walls.

\section{Measurement of tomato fruit tissues}

Basic technique. The stress-relaxation method was first applied to the evaluation of tomato fruit softening process by Kojima et al. (1991). They devised a conical probe for measuring a stress-relaxation curve of tomato fruits. Flat or rounded probes were not suitable for the fresh tissues because the large surface area of the probes generated friction between the probe and tissue surfaces, which confounded the relaxation curve. The conical probe also has an advantage in the measurement of a very small region within the fruit. Since tomato fruits are comprised of different tissues, a probe with a large surface area may integrate the stress-relaxation behavior over a broader area, with a corresponding loss in resolutions.

A Vitrodyne system (Liveco Inc., Burlington, Vt.) was used in our experiments for the stress-relaxation analysis of tomato fruits. The initial load was imposed by the forcing frame via a bellows into which air was pumped by the system controller (Fig. 2). As the bellows extended, the conical probe attached to the arm was lowered. When the probe entered the tissue and attained a prescribed load, it was stopped. When the forcing frame was equipped with a position transducer, the probe was stopped after achieving a depth of $0.6 \mathrm{~mm}$. The latter procedure was superior to the former in that the initial load could be measured as the additional parameter. A strain gauge sensed the deflection of the arm, which was calibrated according to the load. The load data were entered into the

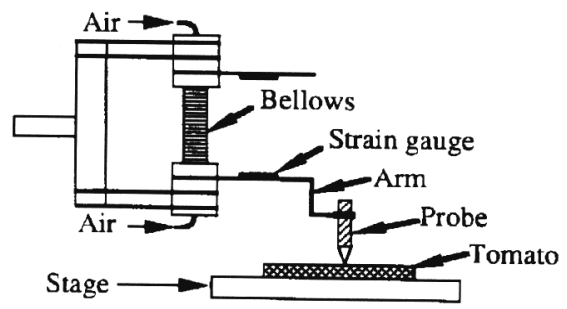

Fig. 2. A schematic diagram of the forcing frame of Vitrodyne system. A conical probe is attached to the arm of the forcing frame. When air is pumped into the bellows. the probe is lowered into the tissue. The load received by the probe is sensed by the strain gauge on the arm. computer at 1 -sec intervals over a total of $60 \mathrm{sec}$. The series of load-decay data (expressed as percent) were used for calculating four stress-relaxation parameters using [Eq. 1]. Four parameters were calculated by a least-square method programmed in $\mathrm{C}$ language (the program is available from us by inquiry). When the forcing frame with an optional transducer was used, the initial load imposed when the probe reached $0.6 \mathrm{~mm}$ yielded the fifth parameter. In this case, [Eq. 2] was used for the calculation of stress-relaxation parameters.

$\operatorname{Load}(g)=R\left(\log _{e} \frac{t+T_{m}}{t+T_{0}}\right)+C$ [Eq. 2]

Note that the load is expressed as grams. [Eq. 2] is superior to [Eq. 1] because of the introduction of the value for the initial load.

A tomato slice ( 7 to $8 \mathrm{~mm}$ thick) was placed on a stage; contact with the tip of probe was achieved by elevating the stage. The lowering rate of the probe was set at $60\left(\approx 10 \mathrm{mmžmin}^{-1}\right)$ (loop number described in the Vitrodyne manuals). Increasing the loop number accelerated the lowering speed. A high loop number caused excessive acceleration of the pro be and introduced an artifact into the calculation of the stress-relaxation parameters.

Typical stress-relaxation curves of green and red pericarp tissues of 'Castlemart' tomato fruits are shown in Fig. 3. The data demonstrate that the green tissues exhibit higher initial load, $\mathrm{C}$ and $\mathrm{T}_{\mathrm{m}}$. The initial load may correspond to the parameter derived from conventional compression methods. Higher initial loads represent higher elastic properties of the tissue. Higher $\mathrm{T}_{\mathrm{m}}$ represents a higher viscosity of the tissue. The data indicate that the red tomato fruits exhibited lower elasticity and viscosity than the green fruit. The chemical analysis of wall polysaccharides reveals that red tomato pericarp tissues contained less pectin and a lower abundance of the higher molecular weight xyloglucans (our unpublished data). The results of chemical analysis of wall polysaccharides are in good agreement with the prediction of stress-relaxation parameters, in that the degradation of wall polysaccharides causes changes in physical properties of the fruit.

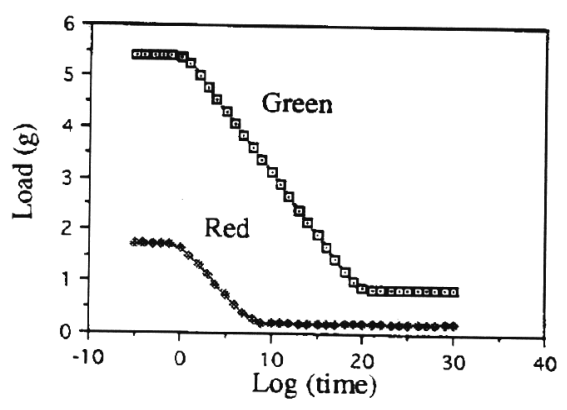

Fig. 3. Stress-relaxation curves for the green and red tomato pericarp tissues. The stressrelaxation parameters and initial loads were determined using four fruit (four measurements each) of the green and red tomatoes. The curves were drawn using the determined parameters by computation.

Changes in stress-relaxation parameters during ripening. Changes in the stress-relaxation parameters during tomato ripening were determined (Kojima et al., 1991). For practical reasons (slow speed of a coprocessor of the computer used), the parameter $\mathrm{C}$ was not used for the calculation-hence, unreliable values for $\mathrm{T}_{\mathrm{m}}$ may have been calculated. Nevertheless, a developmental sequence was revealed when tomato fruits were sliced along the vertical axis and the probe inserted into different tissues within the fruit (i.e., central axis, blossom end, equatorial and shoulder parts of endo- and exo-pericarp tissues). The decrease in $\mathrm{T}_{0}$ appeared first in the middle columella and blossom end of pericarp tissues at the breaker stage and then in the equatorial and shoulder regions of pericarp (Fig. 4). The patterns of decreasing $\mathrm{T}_{0}$ values appeared to be correlated with the reported regional variation in the appearance of the polygalacturonase enzyme responsible for pectin degradation (Tieman and Handa, 1989).

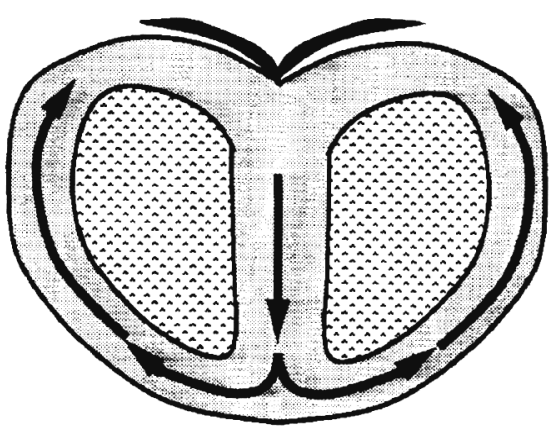

Fig. 4. Changes in stress-relaxation parameters within tomato fruit. A stressrelaxation parameter $\left(T_{0}\right)$ decreased from the center axis via blossom end to shoulder of pericarp tissue as the fruit matured. 


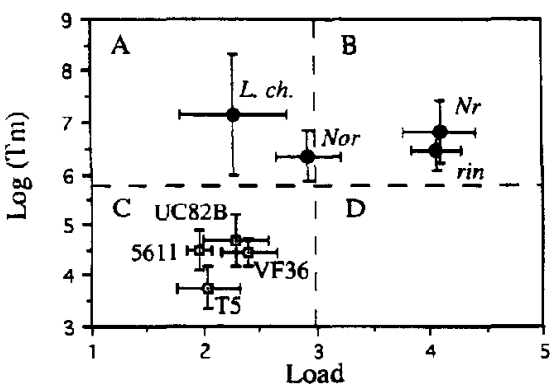

Fig. 5. Initial load and $T_{m}$ palues for ripening mutants and normal varieties. UC82B, VF36, 5611, and T5 represent normal varieties. Nor, $\mathrm{Nr}$ and $\mathrm{rin}$ are ripening mutants. Lycopersicon chmieiewskii (L. ch.) represents the wild type. Capital letters in the figure correspond to those shown in Fig. 7 .

Ripening of mutants. Ripening mutants of tomato fruits were subjected to the stress-relaxation analysis (Fig. 5). Calculation of parameter $\mathrm{C}$ within 2 min enabled the precise calculation for $\mathrm{T}_{\mathrm{m}}$ value. $\mathrm{T}_{\mathrm{m}}$ and initial load were found to be appropriate parameters to characterize fruit tissue textures of the ripening mutants, $\mathrm{Nr}$, rin, and Nor, which neither ripen nor soften according to conventional measurement. The wild-type tomato (Lycopersicon chmieiewskii) also does not express a normal softening process. In commercial varieties of red tomato the fruit pericarp exhibits low $\mathrm{T}_{\mathrm{m}}$ and a low initial load. $N r$ and $\mathrm{rin}$ showed higher $\mathrm{T}_{\mathrm{m}}$ and higher initial load than the normal, indicating these two mutants express contrasting elasticity and viscosity. Nor and $L$. chmieiewskii showed initial loads similar to those of normal varieties, but had distinctly higher $\mathrm{T}_{\mathrm{m}}$ values, indicating that they exhibit higher viscosity than

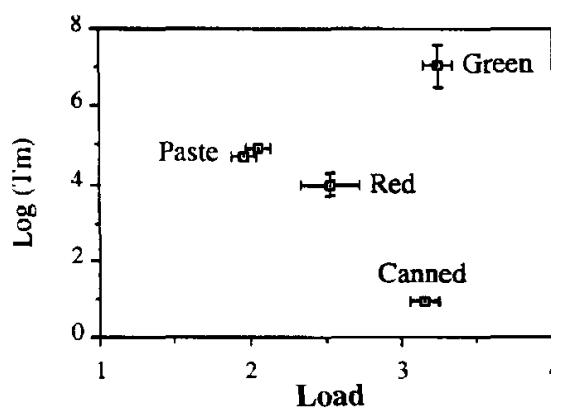

Fig. 6. Initial load and $T_{m}$ values for canned tomato and tomato paste. A conical probe was used for the stress-relaxation analysis of canned tomatogreen and red pericarp tissues. A flat probe was used for the tomato paste. The values obtained with a flat probe should not be directly compared with those obtained with a conical probe.

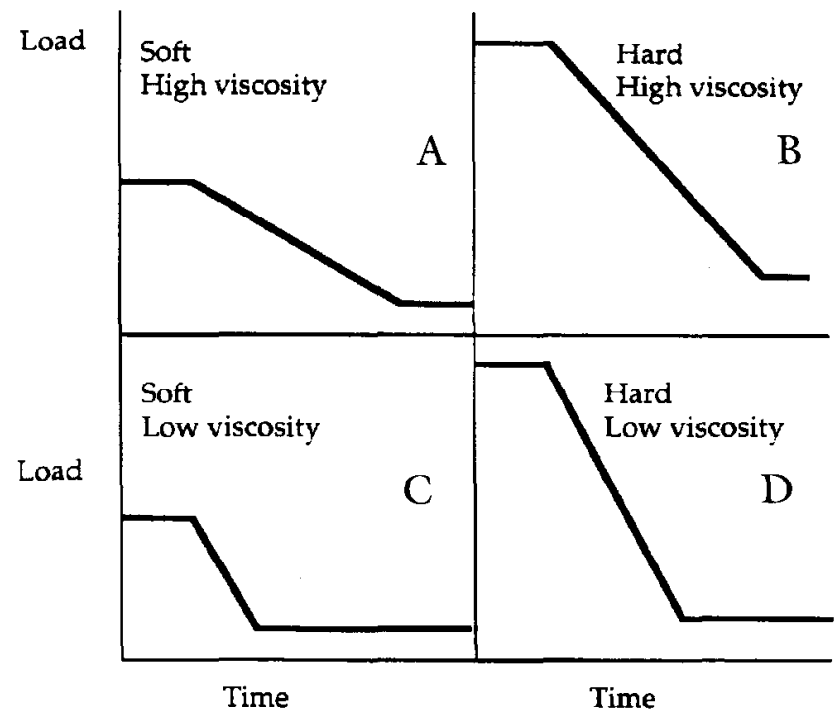

Fig. 7. Classification of tomato tissue texture by the stress-relaxation curve. High initial load represents high elasticity (Firm in a general sense). A high $T_{m}$ value represents high viscosity Combination of two parameters affords four categories. Capital letters shown in Fig. 5 correspond to those in this figure.

the normal, but had similar elasticity. Although the conventional methods for evaluating the firmness of these types demonstrated that they exhibit higher firmness than normal red varieties, the stress-relaxation analy-sis can segregate tomato varieties with abnormal softening sequences into several types.

Canned tomato and paste. Canned tomato and tomato paste also were subjected to the stress-relaxation analysis. The conical probe imposed an insufficient initial load to allow following of the decay response in paste. Therefore, for paste, we used a flat probe (3 $\mathrm{mm}$ in diameter). Fig. 6 compares paste with the data derived from green and red tomatoes. Two different brands of canned tomato paste, purchased at a local retail outlet, were used. The values for Tm and initial loads of two sources of paste were almost identical, suggesting that the qualities of the paste expressed by the stress-relaxation analysis are very similar. Canned whole tomatoes exhibit lower Tm than fresh red tomatoes, but they have similar initial load values, suggesting that processing suppresses the expression of tomato fruit viscosity.

\section{Classification of fruit tissue texture by the stress- relaxation analysis}

The stress-relaxation analysis affords two important mechanical prop- erties of fruit texture-elasticity and viscosity. Elasticity can be represented by the initial load and viscosity by $\mathrm{T}_{\mathrm{m}}$ value. Therefore, the tissue texture can be arranged into four categories: A) low elasticity (soft) and high viscosity; B) high elasticity (firm) and high viscosity; C) low elasticity (soft) and low viscosity; and D) high elasticity (firm) and low viscosity (Fig. 7). The capital letters in the upper panels correspond to those shown in Fig. 5. In the examination of samples including tomato, banana, and avocado, we have not observed the D type.

Estimating fruit firmness by pressing with a thumb is a primitive but simple test. Conventional testing for fruit firmness mimics the thumb test. Pressing a fruit by the thumb is a measure of resistance inherent in the fruit. If the fruit is pressed to a constant depth for a period of time, the thumb test reflects fruit viscosity. However the lack of the ability to maintain a constant pressure and subjectivity inherent in sensory perception mandates mechanical assistance for stress-relaxation analysis.

A procedure for measuring stress relaxation has several advantages. Not only can it detect differences in ripening stages, but it is capable also of assessing variatal differences and detecting variations resulting from cultural practices. Hence, there is the option to determine additional information for describing the properties of the raw product for use in quality 
control. Each measurement can be made routinely in little more than 1 min. Because of the rapid acquisition of values representing components of fruit texture, tomato breeders might find it feasible to incorporate the technique into cultivar improvement programs where the goal is to improve fruit firmness and viscosity.

\section{Literature Cited}

Ahrens, M. J. and D. J. Huber. 1990. Physiology and firmness determination of ripening tomato fruit. Physiol. Plant. 78:814.

Brady, C.J., S.K. Meldrum, and W.B. MC Glasson. 1983. Differential accumulation of the molecular forms of polygalacturonase in tomato mutants. J. Food Biochem. 7:7-14.

Brady, C. J. 1987. Fruit ripening. Annu. Rev. Plant Physiol. 38:155-178.

Fisher R. L. and A. B. Bennett. 1991. Role of cell wall hydrolases in fruit ripening. Annu. Rev. Plant Physiol. 42:675-703.

Hayashi T. 1989. Xyloglucans in the primary cell wall. Annu. Rev. Plant Physiol. 40:139-168.

Huber, D.J 1983a. The role of cell wall hydrolases in fruit softening. Hort. Rev. 5:169-219.

Huber, D.J. 1983b. Polyuronide degradation and hemicellulose modifications in ripening tomato fruit. J. Amer. Soc. Hort. Sci. 108:405-409.

Kojima, K., N. Sakurai, S. Kuraishi, R. Yamamoto, and D.J. Nevins. 1991. Novel technique for measuring tissue firmness within tomato (Lycopersicon esculentum Mill.) fruit. Plant Physiol. 96:545-550.

Lynch, L.J., R.S. Mitchell, and D. J. Casimir. 1959. The chemistry and technology of the preservation of green peas. Adv. Food Res. 9:61-152.

Loescher, W. and D.J. Nevins. 1972. Auxininduced changes in Avena coleoptile cell wall composition. Plant Physiol. 50:556 563.

Masuda, Y. 1990. Auxin-induced cell elongation and cell wall changes. Bot. Mag. Tokyo 103:345-370.

Nishitani, K. and Y. Masuda. 1983. Auxin induced changes in the cell wall xyloglucans:
Effect of auxin on the two different subfractions of xyloglucans in the epicotyl cell wall of Vigna angularis. Plant Cell Physiol. 24:345-355.

Pomeranz, Y. and C.E. Meloan. 1987. Food analysis: Theory and practice. Van Nostrand Reinhold, New York.

Sakurai, N., D.J. Nevins, and Y. Masuda. 1977. Auxin- and hydrogen ion-induced cell wall loosening and cell extension in Avena coleoptile segments. Plant Cell Physiol. 18:371-380.

Sakurai, N. and Y. Masuda. 1978. Auxininduced extension, cell wall loosening and changes in the wall polysaccharide content of barley coleoptile segments. Plant Cell Physiol. 19:1225-1233.

Sakurai, N., K. Nishitani, and Y. Masuda. 1979. Auxin-induced changes in molecular weight of hemicellulosic polysaccharides of Avena coleoptile cell wall. Plant Cell Physiol. 20:1349-1357.

Sakurai, N. 1991. Cell wall functions in growth and development. Bot. Mag. Tokyo 104:235-251.

Somers, G.F. 1965. Viscoelastic properties of storage tissues from potato, apple, and pear. J. Food Sci. 30:922-929.

Tieman, D.M. and A.K. Handa. 1989. Immunocytolocalization of polygalacturonase in ripening tomato fruit. Plant Physiol. 90:17-20.

Wakabayashi, K., N. Sakurai, and S. Kuraishi. 1991. Differential effect of auxin on molecular weight distributions of xyloglucans in cell walls of outer and inner tissues from segments of dark grown squash (Cucurbita maxima Duch.) hypocotyls. Plant Physiol. 95:1070-1076.

Yamamoto, R., K. Shinozaki, and $Y$. Masuda. 1970. Stress-relaxation properties of plant cell walls with special reference to auxin action. Plant Cell Physiol. 11:947956.

Zarra, I. and Y. Masuda. 1979. Growth and cell wall changes in rice coleoptiles growing under different conditions. II. Auxininduced growth in coleoptile segments. Plant Cell Physiol. 20:1125-1133.

\section{Acknowledgments}

We thank R.C. Chetelat and C.M. Rick for providing fresh tomatoes. 